\title{
Tacrolimus-Associated Posterior Reversible Encephalopathy Syndrome after Solid Organ Transplantation
}

\author{
Qisi Wu ${ }^{a}$ Christian Marescaux ${ }^{c}$ Valérie Wolff ${ }^{c}$ Mi-Young Jeung ${ }^{d}$ \\ Romain Kessler ${ }^{\mathrm{e}}$ Valérie Lauer ${ }^{\mathrm{c}}$ Yangmei Chen ${ }^{\mathrm{b}}$ \\ ${ }^{a}$ The Second Affiliated Hospital and ${ }^{b}$ Department of Neurology, The Second Affiliated Hospital, Chongqing \\ Medical University, Chongqing, PR China; ' Stroke Unit and Department of Neurology, University Hospital of \\ Strasbourg, ${ }^{\mathrm{d}}$ Department of Radiology B, University Hospital of Strasbourg, and ${ }^{\mathrm{e}}$ Department of Pulmonology, \\ Nouvel Hôpital Civil, Strasbourg, France
}

\section{Key Words}

Posterior reversible encephalopathy syndrome •

Tacrolimus $\cdot$ Solid organ transplantation

\begin{abstract}
Tacrolimus (TAC) is an immunosuppressant drug discovered in 1984 by Fujisawa Pharmaceutical Co., Ltd. This drug belongs to the group of calcineurin inhibitors, which has been proven highly effective in preventing acute rejection after transplantation of solid organs. However, neurotoxicity and nephrotoxicity are its major adverse effects. Posterior reversible encephalopathy syndrome (PRES) is the most severe and dramatic consequence of calcineurin inhibitor neurotoxicity. It was initially described by Hinchey et al. in 1996 [N Engl J Med 1996;334:494-450]. Patients typically present with altered mental status, headache, focal neurological deficits, visual disturbances, and seizures. Magnetic resonance imaging is the most sensitive imaging test to detect this. With the more deep-going studies done recently, we have learnt more about this entity. It was noted that this syndrome is frequently reversible, rarely limited to the posterior regions of the brain, and often located in gray matter and cortex as
\end{abstract}

well as in white matter. Therefore, in this review, the focus is on the current understanding of clinical recognition, pathogenesis, neuroimaging and management of TAC-associated PRES after solid organ transplantation.

Copyright $\odot 2010$ S. Karger AG, Basel

\section{Introduction}

The introduction of the calcineurin inhibitor (CNI) cyclosporine (CsA), and later of tacrolimus (TAC), with 100 times more potent immunosuppressive activity than that of CsA by weight, revolutionized posttransplantation immunosuppressive therapy in the 1980s [1]. These drugs effectively prevent acute rejection episodes and significantly prolong patient and graft survival $[2,3]$. As demonstrated in large, prospective, randomized, multicenter solid organ transplantation (SOT) trials, when compared with CsA, TAC further reduced the 6-month/ 1 -year incidence of biopsy-proven acute rejection. Posttransplant survival and treatment failure rates in the TAC groups were at least equal to or better than those for CsA. Furthermore, other metabolic benefits were seen in TAC

\section{KARGER}

Fax +4161306 1234 E-Mail karger@karger.ch www.karger.com
(C) 2010 S. Karger AG, Basel

0014-3022/10/0643-0169\$26.00/0

Accessible online at:

www.karger.com/ene
Yangmei Chen

Department of Neurology, The Second Affiliated Hospital

Chongqing Medical University

Chongqing 400016 (PR China)

Tel. +86236369 3694, Fax +86236371 1527, E-Mail wuvictorl1@yahoo.fr 
groups, such as lowered incidence of hyperlipidemia and cosmetic changes (gum hypertrophy, hirsutism) [4-6]. In contrast to 1997 , when $77 \%$ of patients were discharged on CsA, 82\% were started on TAC in 2006 [7]. However, the incidence of neurotoxicity which is one of the major adverse events of CNIs was higher in patients receiving TAC rather than CsA [8]. TAC-induced neurotoxicity has been well documented particularly in SOT recipients. As both sensory-motor functions may be adversely affected, patients thus present with a wide range of neurological and psychiatric disorders. Mild symptoms include tremor, neuralgia, and peripheral neuropathy. Severe symptoms could be manifested as psychoses, hallucinations, cortical blindness, seizures, cerebellar ataxia, motor weakness, or posterior reversible encephalopathy syndrome (PRES) [2, 9-15]. As an uncommon complication related to significant morbidity and mortality if it is not expeditiously recognized [9], TAC-associated PRES after SOT has recently been increasingly reported.

\section{Posterior Reversible Encephalopathy Syndrome}

PRES was initially described by Hinchey et al. [16] in 1996 as a cliniconeuroradiological entity, characterized by typical neurological deficits, distinctive magnetic resonance imaging (MRI) features, and a usually benign clinical course. Although hypertensive urgency, eclampsia, immunosuppressive drugs (CsA and TAC) and acute intermittent porphyria were first reported as predisposing factors causing PRES, it is a syndrome which can have variable causes (table 1 ).

\section{Prevalence and Clinical Features of TAC-Associated PRES in SOT}

The frequency of patients affected by CNI-induced neurotoxicity has been reported to vary from 7 to $32 \%$ [2, 17]. According to emerging research in the USA covering 4,222 patients who had undergone SOT from 1998 to 2006, the overall incidence of PRES after SOT is $0.49 \%$ [18], which is much lower than that suggested by older reports or studies (1-6\%) [19]. However, Wong et al. [20] reported that the incidence of TAC-induced PRES is approximately $1.6 \%$. Minor variation in the PRES incidence was noted between SOT subtypes from $0.34 \%$ in the kidney or kidney-pancreas group to $0.84 \%$ in the small bowel group, but differences were not statistically significant [18].
Table 1. Causes of PRES

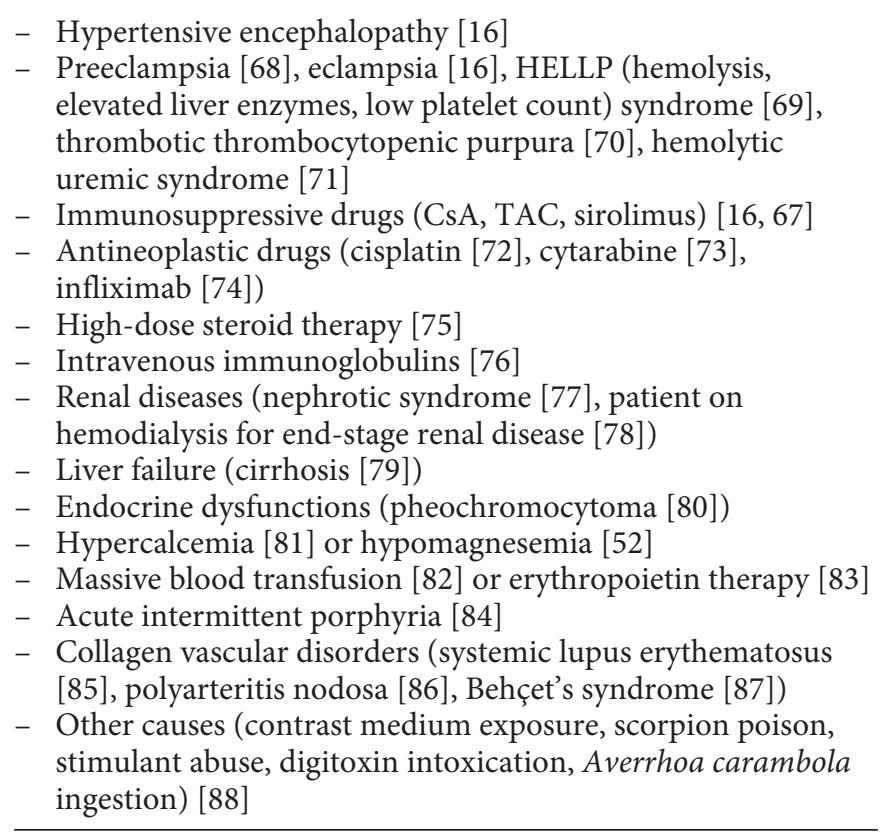

The clinical picture of PRES is characterized by an acute or subacute encephalopathy with headache, vomiting, focal neurological deficits, altered mental status, visual impairment and seizures [21,22]. Seizures may begin focally but usually become generalized. Additionally, in approximately $70-80 \%$ of patients, moderate-to-severe hypertension is observed $[18,23]$. Recent research compared the clinical characteristics of PRES between different SOT subgroups in which statistically significant differences were found. As in patients who had undergone liver transplantation, PRES developed in the first 2 months after the transplantation. These patients had generally normotensive blood pressure and greater brain vasogenic edema, whereas in patients who had undergone kidney transplantation, PRES developed 1 year later. These patients had severe hypertension at presentation but had much less brain vasogenic edema [18, 24]. Normally, clinical symptoms resolve after a mean of 5.3 days [21]. But late recognition of this syndrome, poor control of hypertension, prolonged seizures, the inability to correct or diagnose the triggering metabolic abnormality, or persistence in the use of the culprit drugs may, potentially, result in permanent neurological deficit and cerebral infarcts. The multiple cerebral infarctions may result in early dementia. 

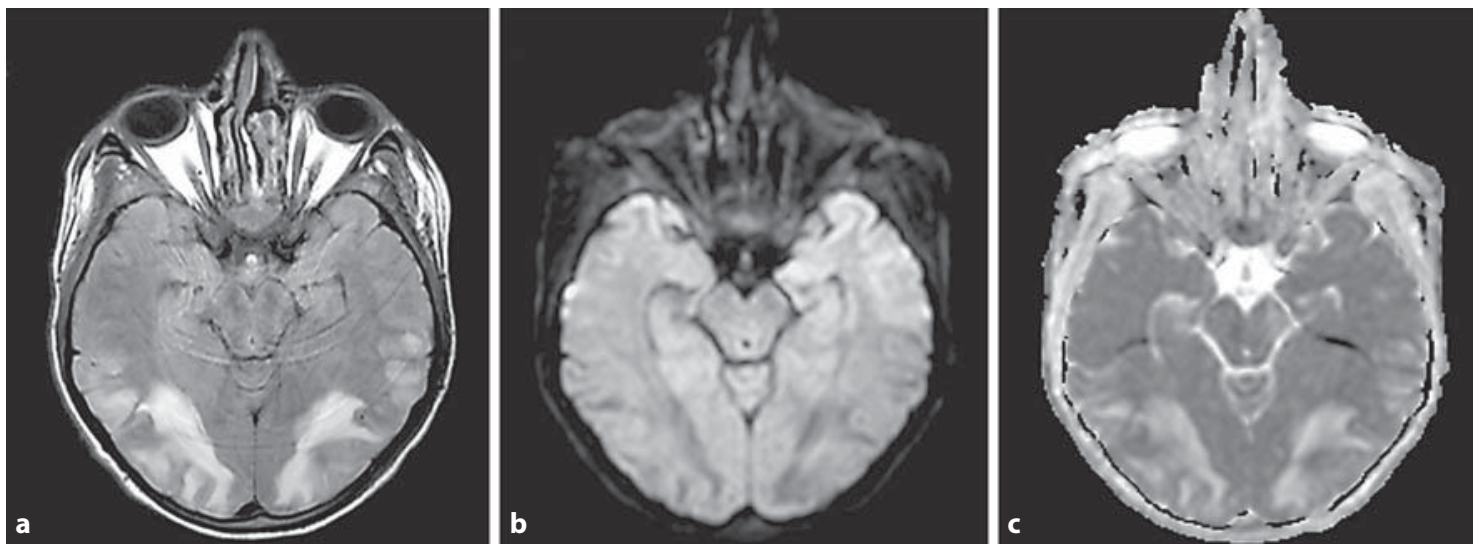

Fig. 1. A 19-year-old patient with mucoviscidosis underwent a bipulmonary and hepatic transplantation. Seven days after the surgery, the patient presented with sudden-onset generalized tonicclonic seizures, altered mental status and headache. Axial MR im-

ages showed a bilateral posterior subcortical hyperintensities on FLAIR. b, c DWI reveal abnormal signal hypointensities in the same region, with high ADC in a pattern typical of PRES.
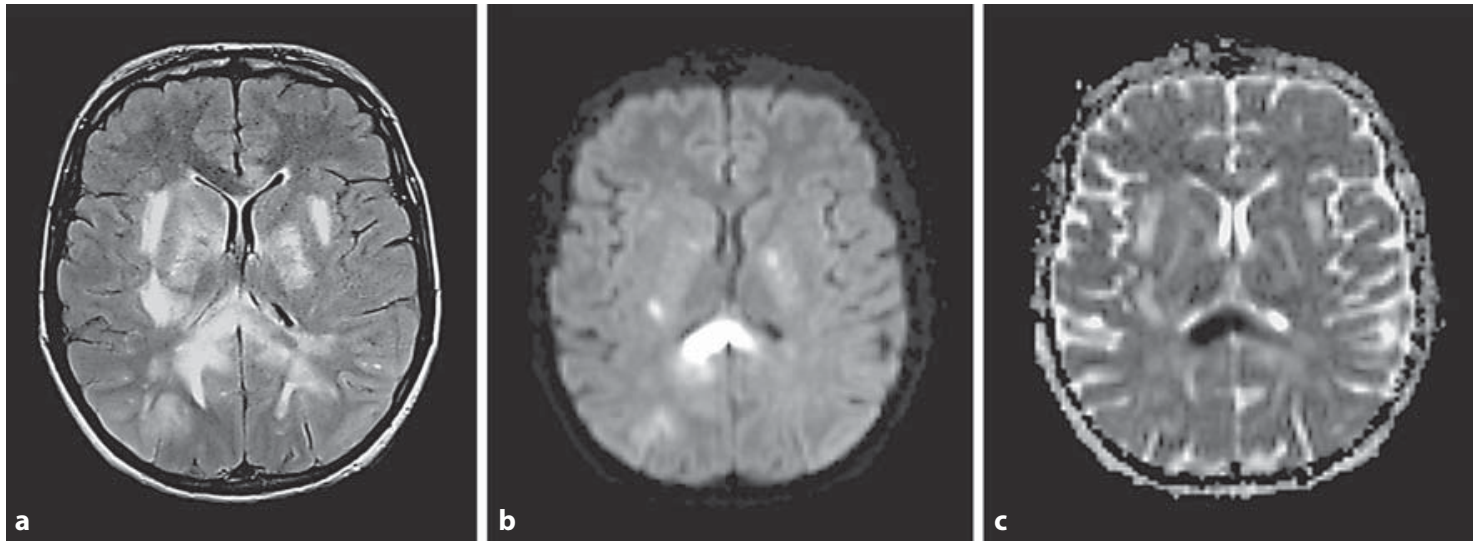

Fig. 2. In the same patient, 2 months after the transplantation, confusion developed again. a FLAIR MR images reveal cerebral hyperintense signal changes in the subcortical white matter of the parietal lobe and deep white matter including internal capsules, insular regions and corpus callosum with predominance in the splenium. Additionally, there are hyperintense signal alternations also located in caudate nucleus. b Corresponding DWI demon- strates increased diffusion particularly in the periventricular white matter and corpus callosum with isointense signal in the rest of the areas. c Except for corpus callosum with reduced ADC values which suggested cytotoxic edema, those areas with increased signal intensity on FLAIR have increased ADC values suggesting a vasogenic edema.

\section{Neuroimaging}

It has been well established that vasogenic edema rather than cytotoxic edema plays a pivotal role in TAC-associated neuroimaging characteristics of PRES supported by MRI manifestations [25-29] (fig. 1). Nevertheless, cases of a coexistence of vasogenic and cytotoxic edema suggesting irreversible damage have been described $[25,28-$ 30] (fig. 2). Therefore, although computed tomography can be used preliminarily to detect hypodense lesions of posterior encephalopathy, MRI is the gold standard of diagnosing this syndrome. Fluid-attenuated inversion recovery (FLAIR) sequence is the most sensitive sequence for recognition of cortical and subcortical edema in PRES where hyperintense signal alterations are more prevalent than on conventional sequences [31]. Furthermore, new MR techniques, including diffusion-weighted MRI (DWI) and apparent diffusion coefficient (ADC) map- 
Fig. 3. A 48-year-old patient with silicosis underwent a bipulmonary transplantation. Five months after the transplantation, the patient suddenly developed confusion. a, b FLAIR demonstrates asymmetric cerebral increased white matter signal intensity affecting cerebellar, parietal and frontal areas. c, d Corresponding $\mathrm{T}_{2}{ }^{*}$ reveals a lesion of decreased signal intensity in the right cerebellum and multiple hypointense signal changes in the two cerebral hemispheres, suggesting hemorrhagic lesions.
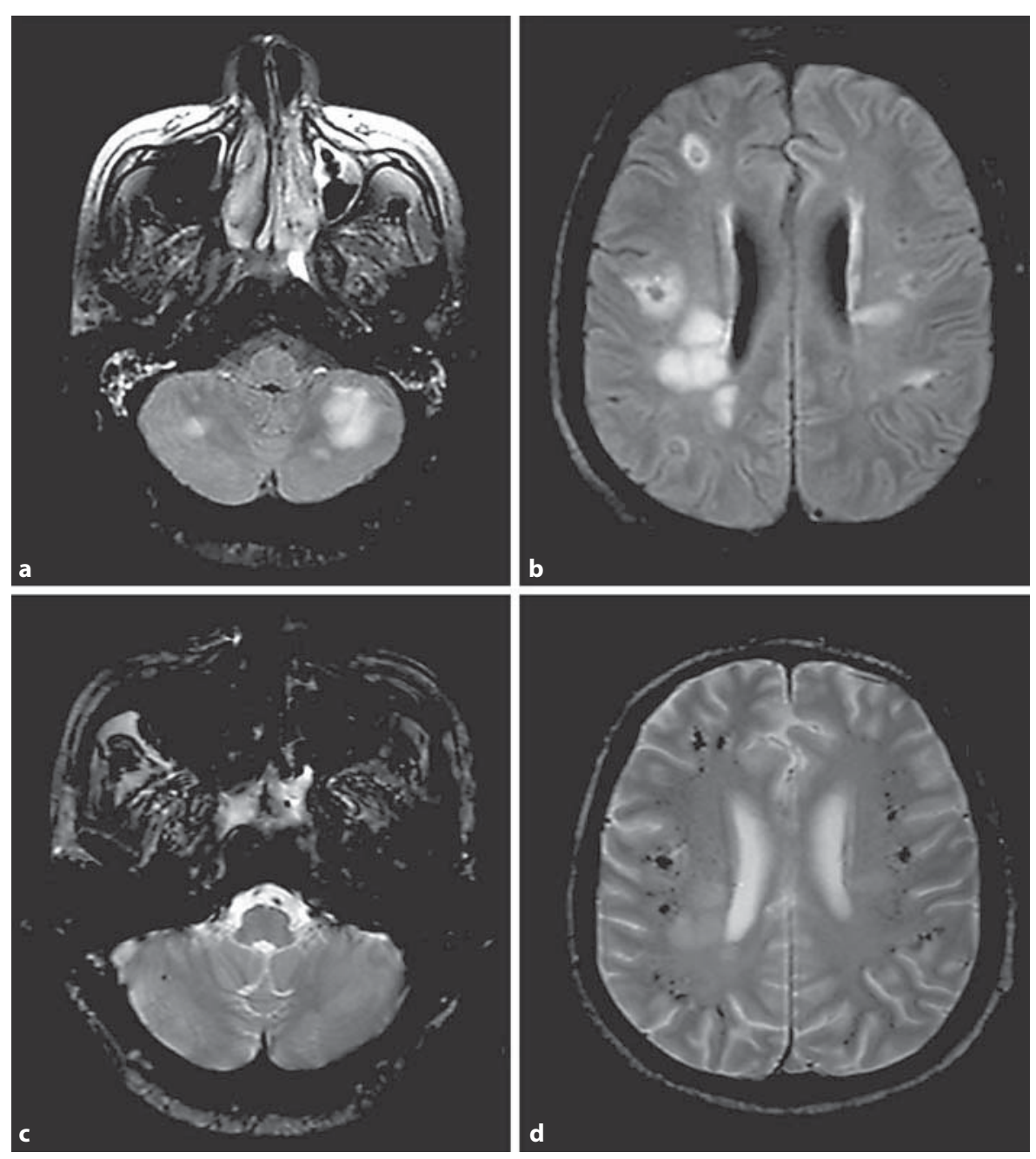

ping, which can be elaborated from DWI, enable the measurement of net movement of water molecules in the brain using different metrics and reliably distinguish the type of edema in these patients [27-29].

In the case of a cytotoxic edema in which water molecules are translated from the extracellular to the intracellular compartment, it is characterized by hyperintensity in diffusion-weighted images and hypointensity in ADC mapping (fig. 2b, c) whereas in the case of a vasogenic edema, where there is an increase in the extracellular water and thus an increased diffusion, DWI shows an iso- or hyperintense signal but in ADC maps the signal intensity is increased [29] (fig. 2b, c). However, a significant debate has developed in recent literature regarding the various DWI phenomena of PRES. In the patients with PRES, although the most common appearances on diffusion-weighted images are isointense lesions result- ing from a balance of $\mathrm{T}_{2}$ effects and increased water diffusibility, a hypo- and hyperintense signal can also be visualized due to further increased diffusibility and $\mathrm{T}_{2}$ shine-through effect, respectively [25, 32-34] (fig. 1b, 2b). In this regard, the quantification of $\mathrm{ADC}$ becomes essential for the discrimination of this vasogenic edema from cytotoxic edema in these patients. Covarrubias et al. [35] found that pseudonormalized normal ADC values in the areas of DWI hyperintensity may represent the earliest sign of nonreversibility as severe vasogenic edema progresses to cytotoxic edema with a worse outcome in patients with PRES. Mueller-Mang et al. [32], on the other hand, showed that the clinical outcome in their patients did not differ according to DWI abnormalities. In addition, abnormal gadolinium enhancement and hemorrhage (fig. 3c, d) were also described as less common manifestations in PRES. Hence, it is advisable that the 
sequences (FLAIR, DWI and ADC) and even $\mathrm{T}_{2}{ }^{*}$ and gadolinium-enhanced $\mathrm{T}_{1}$-weighted imaging where the degree of enhancement could relate to the cause of PRES (CsA or TAC) should be included in MR protocols for suspected PRES, not only for the correct identification of the lesions but also for preventing deleterious workups or therapies $[25,29]$.

Apart from a significantly higher number of involved brain regions and a tendency for basal ganglia involvement in patients with PRES associated with preeclampsia-eclampsia, the MRI appearance of patients with PRES does not seem to be influenced by predisposing risk factors [32]. Typically, the lesions of PRES reported in the literature are bilateral and symmetric in the cortical and subcortical regions of the parietal and occipital lobes (fig. 1a). However, in most patients, lesions were rarely limited to the posterior regions of the brain and asymmetric involvement of at least one brain region (fig. 3a, b) or even a unilateral variant was observed [25, 32]. Posterior frontal (51.5-78.9\%), temporal (33-68.4\%), cerebel$\operatorname{lum}(33.3-43 \%)$, brainstem (18.4-30\%), thalamus (30.3\%), and basal ganglia (11.8\%) can be involved, which used to be called atypical PRES but with a higher incidence than commonly perceived $[16,25,28,31,32]$ (fig. 2a, 3a, b). Hence, McKinney et al. [25] suggested that the term 'multifocal' or simply removing 'posterior' from the term 'posterior reversible encephalopathy syndrome' may be a more appropriate terminology given the common involvement of the regions supplied by the anterior circulation.

\section{Pathogenesis}

It is known that neurological alterations after $\mathrm{CNI}$ therapy are associated with brain structures showing high calcineurin expression [36]. But the precise mechanism for the development of subcortical and cortical edema in PRES is still incompletely understood. From a historical perspective, two major hypotheses on the pathology of PRES are currently being discussed in the literature: the hyperperfusion and hypoperfusion theory. The first hypothesis which is more current and popular refers to systemic hypertension. Severe hypertension leads to the transient disruption of the autoregulation system consisting of a myogenic and a neurogenic response which will lead to cerebral vasodilatation; this, therefore, allows extravasation of fluid and blood into the brain parenchyma [37] and causes vasogenic cerebral edema. The main evidence supporting this theory comes from stud- ies with single photon emission tomography [38] and as mentioned earlier DWI [27]. However, an inconsistency of this hypothesis is that many patients develop the syndrome with relative normotension.

Alternatively, vasospasm with brain hypoperfusion and presumed ischemia has been demonstrated. This theory is supported by the magnetic resonance angiography evaluation of a patient with CsA-induced PRES with documented prolonged reversible vasospasm [39] and it was noted that PRES occurred in $9 \%$ of patients with reversible cerebral vasoconstriction syndrome [40]. Several autopsy studies confirmed a predominance of ischemic microinfarcts or fibrinoid necrosis and cerebral vasculitis may occur [41-43]. Moreover, Bartynski and Boardman [24] reported decreased blood volume in reversible posterior leukoencephalopathy syndrome lesions on MRI perfusion coupled with a high rate of vasculopathy which was also seen in 2 cases of a recent series of patients with PRES and was considered to be responsible for some of the irreversible injury, presumably ischemic in nature [21, 44]. These features suggest that the primary mechanism of PRES could be associated with reduced cerebral flow. In contrast, hypertension, at some level, may reduce the vasogenic edema and exert a protective effect limiting the development of PRES [24]. Additionally, experimental data have indicated direct cytotoxic effects on the brain capillary endothelial cells with TAC which is similar, but less severe than those of CsA [45]. However, because of the large number of different chemotherapeutic and immunosuppressant agents that are associated with PRES, some publications focused on an immunogenic process as a theory for possible endothelial dysfunction or demyelinization in patients with PRES [46-49]. This seems to be specifically associated with CNIs (TAC and CsA). According to a recent article by Bartynski [46] and along with the previously described immunogenic theory, enhanced systemic endothelial activation, leukocyte trafficking, and vasoconstriction, alone or in combination, would result in brain and systemic hypoperfusion in the majority of patients with PRES. Thus, we cannot deny that immune-mediated states may contribute to the increased risk of PRES in a subset of patients. Moreover, it has been demonstrated that TAC has a more significant effect on causing urinary magnesium wasting and hypomagnesemia when compared with CsA, which might partly explain the higher incidence of renal impairment and encephalopathy in patients receiving TAC [50-52]. Hypomagnesemia, which has been reported to predispose to hypertension, renal impairment, and TACinduced encephalopathy after transplantation [50, 52], 
could promote vasoconstriction [53]. But the precise mechanism by which hypomagnesemia causes encephalopathy is not clear. Therefore, we are in favor of the opinion voiced by Lee et al. [54] that although there are a variety of superficially unrelated precipitants involved in the process, all the triggers are presumably unified by a final common pathway, possibly dysfunction of cerebral autoregulation.

\section{Management}

As an effective medication for eclampsia seizures, the mechanism of action of magnesium sulfate has been further studied, in which the vasodilatory effect in the peripheral vasculature and the cerebrovasculature along with its effect on protecting the blood-brain barrier and possible effect on the cerebral endothelium to limit vasogenic edema has been proposed [55]. Consequently, a further discussion of magnesium supplementation and its potential in treating or preventing other brain injury disorders, even TAC-associated PRES, has recently been raised $[55,56]$. However, the fact that mesenteric arteries are significantly more sensitive to magnesium sulfate as a vasodilator than the cerebral arteries [57] made it difficult to achieve consensus regarding the best possible use of magnesium supplementation in treating or preventing PRES, and there is controversy regarding the safety of treatment for neurological conditions as well as the specific mechanisms of action of magnesium sulfate remain unclear. Nevertheless, close serum magnesium level monitoring has been strongly recommended so as to avoid the possible TAC-associated complications induced by hypomagnesemia [50].

TAC-associated PRES may be reversed in most patients by substantially reducing the dosage of TAC or discontinuing the drug. But the conflicts between the prevention of episodes of rejection after transplantation and neurotoxicity from TAC always bewilder physicians. Therefore, TAC therapeutic drug monitoring still remains the main approach to aid physicians to obtain the ideal balance between therapeutic efficacy and the occurrence of adverse events, which still has its limitations. A well-recognized phenomenon is that immunosuppressant blood levels do not appear to correlate with PRES and some patients have experienced permanent or even fatal neurological damage even after dose reduction or discontinuation [58], suggesting the possibility of idiosyncrasy. A trial following 827 adult liver transplant recipients who received TAC as their primary immuno- suppressant over a 5-year period focused on those who required a switch of TAC because of neurotoxic side effects [59]. The findings of this retrospective study confirmed the existence of this neurotoxicity-prone population, who should be carefully considered as a high-risk group for this undesirable CNI complication. Furthermore, research of Yanagimachi et al. [60] and Yamauchi et al. [61] showed that the polymorphisms in CYP3A5, $A B C B 1$ and MDRI genes were linked to CNI-related neurotoxicity. It was reported that patients carrying at least 1 CYP3A5* 1 allele have a lower TAC concentration to dose ratio when compared with nonexpressors $\left(\mathrm{CYP} 3 \mathrm{~A} 5 * 3 /{ }^{*} 3\right)$ in kidney, liver, lung, and heart transplant recipients [62]; it is obvious that individual pharmacogenetics could affect whole blood TAC concentrations and, consequently, increasing TAC concentrations may lead to an increase in drug-related adverse effects [63]. These preliminary results explained the interindividual variability of neurotoxicity at a genetic level and, furthermore, indicated that genetic polymorphisms might be useful to predict the susceptibility of a patient with an increased risk for TAC-related neurotoxicity rather than a pure concentration-based approach [64]. In this high-risk group for undesirable TAC complications, choosing a different immunosuppressive protocol or aiming at a lower threshold for stopping TAC might eventually allow to reduce the incidence of TAC-associated PRES and improve clinical outcome [64]. Some physicians recommended that CsA should be chosen when patients experience TAC-related adverse events [65]. Moreover, sirolimus was noted without early or late episodes of major neurotoxicity when used in heart transplant recipients [66]. It was proven that it could be relatively safely used in SOT patients with severe neurological symptoms ascribed to or exacerbated by CNIs [2]. However, in patients after blood stem cell transplant, a case of PRES due to sirolimus was recently reported [67]. Additionally, numerous ongoing studies aim to determine the most effective immunosuppressive protocols while minimizing drug-related side effects. Some studies have investigated the impact of the TAC formulation on reducing TAC-associated side effects. A once-daily extended release formulation of TAC has been developed, which has been tested in conversion studies in both stable and novo kidney and liver transplant recipients. The result showed that it is equally efficacious but has a similar toxicity profile as the conventional TAC formulation when the same trough levels are targeted $[63,64]$. 


\section{Conclusions}

PRES induced by TAC can usually be diagnosed on the basis of a characteristic clinical and radiographic pattern and is usually reversible by reducing the dosage or withholding the drug for a few days. Failure to recognize its heralding symptoms may potentially increase morbidity in SOT. However, by studying this entity in a deep-going way, it was discovered that this syndrome is frequently reversible, rarely limited to the posterior regions of the brain, and often located in the gray matter and cortex as well as the white matter [21]. Future studies are warranted to fully understand the clinical spectrum and underlying pathophysiology of this disorder. With regard to management, there is a tendency that personalized drug therapy with novel approaches in clinical TAC therapeutic drug monitoring will better predict the dose-concentration-response relationship, and a close serum magnesium level monitoring might also contribute to prevent immunosuppressant neurotoxicity and finally improve patient care.

\section{References}

1 Jacobson P, Uberti J, Davis W, Ratanatharathorn V: Tacrolimus: a new agent for the prevention of graft-versus-host disease in hematopoietic stem cell transplantation. Bone Marrow Transplant 1998;22:217-225.

-2 Forgacs B, Merhav HJ, Lappin J, Mieles L: Successful conversion to rapamycin for calcineurin inhibitor-related neurotoxicity following liver transplantation. Transplant Proc 2005;37:1912-1914.

-3 Saner FH, Nadalin S, Radtke A, Sotiropoulos GC, Kaiser GM, Paul A: Liver transplantation and neurological side effects. Metab Brain Dis 2009;24:183-187.

-4 Nashan B: Is acute rejection the key predictor for long-term outcomes after renal transplantation when comparing calcineurin inhibitors? Transplant Rev (Orlando) 2009;23: $47-52$.

5 Scott LJ, McKeage K, Keam SJ, Plosker GL: Tacrolimus: a further update of its use in the management of organ transplantation. Drugs 2003;63:1247-1249.

-6 Woodroffe R, Yao GL, Meads C, Bayliss S, Ready A, Raftery J, Taylor RS: Clinical and cost-effectiveness of newer immunosuppressive regimens in renal transplantation: a systematic review and modelling study. Health Technol Assess 2005;9:1-179.

7 Womer KL, Kaplan B: Recent developments in kidney transplantation - a critical assessment. Am J Transplant 2009;9:1265-1271.

-8 Veroux P, Veroux M, Puliatti C, Morale W, Cappello D, Valvo M, Macarone M: Tacrolimus-induced neurotoxicity in kidney transplant recipients. Transplant Proc 2002;34: 3188-3190.

$\checkmark 9$ Hodnett P, Coyle J, O’Regan K, Maher MM, Fanning N: PRES (posterior reversible encephalopathy syndrome), a rare complication of tacrolimus therapy. Emerg Radiol 2009;16:493-496

10 Bechstein WO: Neurotoxicity of calcineurin inhibitors: impact and clinical management. Transpl Int 2000;13:313-326.
-11 Sierra-Hidalgo F, Martínez-Salio A, Moreno-García S, de Pablo-Fernández E, Correas-Callero E, Ruiz-Morales J: Akinetic mutism induced by tacrolimus. Clin Neuropharmacol 2009;32:293-294.

12 Lee SH, Kim BC, Yang DH, Park MS, Choi SM, Kim MK, Cho KH: Calcineurininhibitor-mediated bilateral hippocampal injury after bone marrow transplantation. J Neurol 2008;255:929-931.

13 Higuchi K, Kimura O, Furukawa T, Kinoshita H, Chujo S, Iwai N: FK506 induces the atrophy of enteric ganglia in small bowel transplantation, which can be prevented by the neuropeptide bombesin. Transplant Proc 2006;38:1823-1824.

14 Bernstein L, Daviss SR: Organic anxiety disorder with symptoms of akathisia in a patient treated with the immunosuppressant FK506. Gen Hosp Psychiatry 1992;14:210-211.

15 Rifai K, Kirchner GI, Bahr MJ, Cantz T, Rosenau J, Nashan B, Klempnauer JL, Manns MP, Strassburg CP: A new side effect of immunosuppression: high incidence of hearing impairment after liver transplantation. Liver Transpl 2006;12:411-415.

16 Hinchey J, Chaves C, Appignani B, Breen J, Pao L, Wang A, Pessin M, Lamy C, Mas JLM, Caplan LR: A reversible posterior encephalopathy syndrome. N Engl J Med 1996;334: 494-500.

$>_{17}$ Jain AB, Fung JJ, Todo S, Reyes J, Selby R, Irish W, Doyle H, Abu-Elmagd K, Casavilla A, Nour B, et al: One thousand consecutive FK506 or CsA, and the incidence of renal complications adverse events. Transplant Proc 1995;27:1099-1104.

18 Bartynski WS, Tan HP, Boardman JF, Shapiro R, Marsh JW: Posterior reversible encephalopathy syndrome after solid organ transplantation. AJNR Am J Neuroradiol 2008;29:924-930.

19 Berden JH, Hoitsma AJ, Merx JL, Keyser A: Severe central-nervous system toxicity associated with cyclosporin. Lancet 1985;1:219220 .
20 Wong R, Beguelin GZ, de Lima M, Giralt SA, Hosing C, Ippoliti C, Forman AD, Kumar AJ, Champlin R, Couriel D: Tacrolimus-associated posterior reversible encephalopathy syndrome after allogenic hematopoietic stem cell transplantation. Br J Haematol 2003;122:128-134.

21 Lee VH, Wijdicks EF, Manno EM, Rabinstein AA: Clinical spectrum of reversible posterior leukoencephalopathy syndrome. Arch Neurol 2008;65:205-210.

22 Striano P, Striano S, Tortora F, De Robertis E, Palumbo D, Elefante A, Servillo G: Clinical spectrum and critical care management of posterior reversible encephalopathy syndrome (PRES). Med Sci Monit 2005;11: CR549-553.

23 Bartynski WS: Posterior reversible encephalopathy syndrome. 1. Fundamental imaging and clinical features. AJNR Am J Neuroradiol 2008;29:1036-1042.

24 Bartynski WS, Boardman JF: Catheter angiography, MR angiography, and MR perfusion in posterior reversible encephalopathy syndrome. AJNR Am J Neuroradiol 2008;29: 447-455.

25 McKinney AM, Short J, Truwit CL, McKinney ZJ, Kozak OS, SantaCruz KS, Teksam M: Posterior reversible encephalopathy syndrome: incidence of atypical regions of involvement and imaging findings. AJR Am J Roentgenol 2007;189:904-912.

26 Ahn KJ, Lee JW, Hahn ST, Yang DW, Kim PS, Kim HJ, Kim CC: Diffusion-weighted MRI and ADC mapping in FK506 neurotoxicity. Br J Radiol 2003;76:916-919.

-27 Doelken M, Lanz S, Rennert J, Alibek S, Richter G, Doerfler A: Differentiation of cytotoxic and vasogenic edema in a patient with reversible posterior leukoencephalopathy syndrome using diffusion-weighted MRI. Diagn Interv Radiol 2007;13:125-128. 
28 Donmez FY, Basaran C, Kayahan Ulu EM, Yildirim M, Coskun M: MRI features of posterior reversible encephalopathy syndrome in 33 patients. J Neuroimaging 2008, E-pub ahead of print.

-29 Finocchi V, Bozzao A, Bonamini M, Ferrante M, Romano A, Colonnese C, Fantozzi LM: Magnetic resonance imaging in posterior reversible encephalopathy syndrome: report of three cases and review of literature. Arch Gynecol Obstet 2005;271:79-85.

-30 Benziada-Boudour A, Schmitt E, Kremer S, Foscolo S, Rivière AS, Tisserand M, Boudour A, Bracard S: Posterior reversible encephalopathy syndrome: a case of unusual diffusion-weighted MR images. J Neuroradiol 2009;36:102-105.

-31 Casey SO, Sampaio RC, Michel E, Truwit CL: Posterior reversible encephalopathy syndrome: utility of fluid-attenuated inversion recovery MR imaging in the detection of cortical and subcortical lesions. AJNR Am J Neuroradiol 2000;21:1199-1206.

-32 Mueller-Mang C, Mang T, Pirker A, Klein K, Prchla C, Prayer D: Posterior reversible encephalopathy syndrome: do predisposing risk factors make a difference in MRI appearance? Neuroradiology 2009;51:373-383.

>33 Gray L, MacFall J: Overview of diffusion imaging. Magn Reson Imaging Clin North Am 1998;6:125-138.

>34 Provenzale JM, Petrella JR, Cruz LC Jr, Wong JC, Engelter S, Barboriak DP: Quantitative assessment of diffusion abnormalities in posterior reversible encephalopathy syndrome. AJNR Am J Neuroradiol 2001;22: 1455-1461.

-35 Covarrubias DJ, Luetmer PH, Campeau NG: Posterior reversible encephalopathy syndrome: prognostic utility of quantitative diffusion-weighted MR images. AJNR Am Neuroradiol 2002;23:1038-1048

-36 Kaminska B, Figiel I, Pyrzynska B, Czajkowski R, Mosieniak G: Treatment of hippocampal neurons with cyclosporin A results in calcium overload and apoptosis which are independent of NMDA receptor activation. Br J Pharmacol 2001;133:997-1004.

>37 Servillo G, Bifulco F, De Robertis E, Piazza O, Striano P, Tortora F, Striano S, Tufano R: Posterior reversible encephalopathy syndrome in intensive care medicine. Intensive Care Med 2007;33:230-236.

-38 Apollon KM, Robinson JN, Schwartz RB, Norwitz ER: Cortical blindness in severe preeclampsia: computed tomography, magnetic resonance imaging, and single-photonemission computed tomography findings. Obstet Gynecol 2000;95:1017-1019.

>39 Lin JT, Wang SJ, Fuh JL, Hsiao LT, Lirng JF, Chen PM: Prolonged reversible vasospasm in cyclosporin A-induced encephalopathy. AJNR Am J Neuroradiol 2003;24:102-104.
40 Ducros A, Boukobza M, Porcher R, Sarov M, Valade D, Bousser MG: The clinical and radiological spectrum of reversible cerebral vasoconstriction syndrome: a prospective series of 67 patients. Brain 2007;130:3091-3101.

41 Schaefer PW, Buonanno FS, Gonzalez RG, Schwamm LH: Diffusion-weighted imaging discriminates between cytotoxic and vasogenic edema in a patient with eclampsia. Stroke 1997;28:1082-1085.

42 Pizzolato GP, Sztajzel R, Burkhardt K, Megret $\mathrm{M}$, Borisch B: Cerebral vasculitis during FK 506 treatment in a liver transplant patient. Neurology 1998;50:1154-1157.

43 Kheir JN, Lawlor MW, Ahn ES, Lehmann L, Riviello JJ, Silvera VM, McManus M, Dunn Folkerth R: Neuropathology of a fatal case of posterior reversible encephalopathy syndrome. Pediatr Dev Pathol 2010, E-pub ahead of print

44 Elkind MS: Reversible posterior leukoencephalopathy (and vasculopathy?) syndrome. Arch Neurol 2008;65:1135.

$\checkmark 45$ Kochi S, Takanaga H, Matsuo H, Ohtani H, Naito M, Tsuruo T, Sawada Y: Induction of apoptosis in mouse brain capillary endothelial cells by cyclosporin A and tacrolimus. Life Sci 2000;66:2255-2260.

46 Bartynski WS: Posterior reversible encephalopathy syndrome. 2. Controversies surrounding pathophysiology of vasogenic edema. AJNR Am J Neuroradiol 2008;29: 1043-1049.

47 Horbinski C, Bartynski WS, Carson-Walter E, Hamilton RL, Tan HP, Cheng S: Reversible encephalopathy after cardiac transplantation: histologic evidence of endothelial activation, T-cell specific trafficking, and vascular endothelial growth factor expression. AJNR Am J Neuroradiol 2009;30:588-590.

48 Lavigne CM, Shrier DA, Ketkar M, Powers JM: Tacrolimus leukoencephalopathy: a neuropathologic confirmation. Neurology 2004;63:1132-1133.

49 Thyagarajan GK, Cobanoglu A, Johnston W: FK506-induced fulminant leukoencephalopathy after single-lung transplantation. Ann Thorac Surg 1997;64:1461-1464.

50 Aisa Y, Mori T, Nakazato T, Shimizu T, Yamazaki R, Ikeda Y, Okamoto S: Effects of immunosuppressive agents on magnesium metabolism early after allogeneic hematopoietic stem cell transplantation. Transplantation 2005;80:1046-1050.

51 Ghaus N, Bohlega S, Rezeig M: Neurological complications in liver transplantation. Neurol 2001;248:1042-1048.

52 Thompson CB, June CH, Sullivan KM, Thomas ED: Association between cyclosporine neurotoxicity and hypomagnesaemia. Lancet 1984;2:1116-1120.

53 Faragó M, Szabó C, Dóra E, Horváth I, Kovách AG: Contractile and endotheliumdependent dilatory responses of cerebral arteries at various extracellular magnesium concentrations. J Cereb Blood Flow Metab 1991;11:161-164.
54 Lee VH, Wijdicks EF, Manno EM, Rabinstein AA: Reversible posterior leukoencephalopathy syndrome - reply. Arch Neurol 2008;65:1136.

55 Euser AG, Cipolla MJ: Magnesium sulfate for the treatment of eclampsia: a brief review. Stroke 2009;40:1169-1175.

56 Courand PY, Christin F, Ben Cheikh A, Baillon JJ, Ber CE, Rimmelé T: Posterior reversible encephalopathy related to tacrolimus in a liver transplanted HIV patient. Gastroenterol Clin Biol 2010;34:29-34

57 Euser AG, Cipolla MJ: Resistance artery vasodilation to magnesium sulfate during pregnancy and the postpartum state. Am J Physiol Heart Circ Physiol 2005;288:H1521H1525.

58 Heidenhain C, Puhl G, Neuhaus P: Late fulminant posterior reversible encephalopathy syndrome after liver transplant. Exp Clin Transplant 2009;7:180-183.

59 DiMartini A, Fontes P, Dew MA, Lotrich FE, de Vera M: Age, model for end-stage liver disease score, and organ functioning predict posttransplant tacrolimus neurotoxicity. Liver Transpl 2008;14:815-822.

60 Yanagimachi M, Naruto T, Tanoshima R, Kato H, Yokosuka T, Kajiwara R, Fujii H, Tanaka F, Goto H, Yagihashi T, Kosaki K, Yokota S: Influence of CYP3A5 and ABCB1 gene polymorphisms on calcineurin inhibitor-related neurotoxicity after hematopoietic stem cell transplantation. Clin Transplant 2009, E-pub ahead of print.

61 Yamauchi A, Ieiri I, Kataoka Y, Tanabe M, Nishizaki T, Oishi R, Higuchi S, Otsubo K, Sugimachi K: Neurotoxicity induced by tacrolimus after liver transplantation: relation to genetic polymorphisms of the ABCB1 (MDR1) gene. Transplantation 2002;74:571578.

62 Hesselink DA, van Gelder T, van Schaik RHN: The pharmacogenetics of calcineurin inhibitors: one step closer toward individualized immunosuppression? Pharmacogenomics 2005;6:323-337.

63 Wallemacq P, Armstrong VW, Brunet M, Haufroid V, Holt DW, Johnston A, Kuypers D, Le Meur Y, Marquet P, Oellerich M, Thervet $\mathrm{E}$, Toenshoff $\mathrm{B}$, Undre $\mathrm{N}$, Weber LT, Westley IS, Mourad M: Opportunities to optimize tacrolimus therapy in solid organ transplantation: report of the European consensus conference. Ther Drug Monit 2009; 31:139-152.

-64 de Jonge H, Naesens M, Kuypers DR: New insights into the pharmacokinetics and pharmacodynamics of the calcineurin inhibitors and mycophenolic acid: possible consequences for therapeutic drug monitoring in solid organ transplantation. Ther Drug Monit 2009;31:416-435.

-65 Filler G: Calcineurin inhibitors in pediatric renal transplant recipients. Paediatr Drugs 2007;9:165-174. 
-66 Van de Beek D, Kremers WK, Kushwaha SS, McGregor CG, Wijdicks EF: No major neurologic complications with sirolimus use in heart transplant recipients. Mayo Clin Proc 2009;84:330-332.

67 Moskowitz A, Nolan C, Lis E, Castro-Malaspina $H$, Perales MA: Posterior reversible encephalopathy syndrome due to sirolimus. Bone Marrow Transplant 2007;39:653-654.

68 Kauntia R, Valsalan R, Seshadri S, Pandit VR: Late postpartum preeclampsia with posterior reversible encephalopathy syndrome. Indian J Med Sci 2009;63:508-511.

-69 Kono Y, Nakamori T, Imafuku I, Kunimoto M, Takei M, Kusaba T: 31-year-old gravid woman of reversible posterior leukoencephalopathy syndrome associated with HELLP syndrome after labor. Rinsho Shinkeigaku 2005;45:317-320.

70 Burrus TM, Wijdicks EF, Rabinstein AA: Brain lesions are most often reversible in acute thrombotic thrombocytopenic purpura. Neurology 2009;73:66-70.

71 Bennett B, Booth T, Quan A: Late onset seizures, hemiparesis and blindness in hemolytic uremic syndrome. Clin Nephrol 2003; 59:196-200.

72 Ito Y, Arahata Y, Goto Y, Hirayama M, Nagamutsu M, Yasuda T, Yanagi T, Sobue G: Cisplatin neurotoxicity presenting as reversible posterior leukoencephalopathy syndrome. AJNR Am J Neuroradiol 1998;19: 415-417.
73 Patel AG, Rao R: Transient Ara-C leukoencephalopathy: MR findings. J Comput Assist Tomogr 1996;20:161-162.

74 Zamvar V, Sugarman ID, Tawfik RF, Macmullen-Price J, Puntis JW: Posterior reversible encephalopathy syndrome following infliximab infusion. J Pediatr Gastroenterol Nutr 2009;48:102-105.

75 Irvin W, MacDonald G, Smith JK, Kim WY Dexamethasone-induced posterior reversible encephalopathy syndrome. J Clin Oncol 2007;25:2484-2486.

76 Govindarajan R, Adusumilli J, Baxter DL, El-Khoueiry A, Harik SI: Reversible posterior leukoencephalopathy syndrome induced by RAF kinase inhibitor BAY 43 9006. J Clin Oncol 2006;24:e48.

77 Nishida M, Sato H, Kobayashi N, Morimoto M, Hamaoka K: Wernicke's encephalopathy in a patient with nephritic syndrome. Eur J Pediatr 2009;168:731-734.

78 Ergün T, Lakadamyali H, Yilmaz A: Recurrent posterior reversible encephalopathy syndrome in a hypertensive patient with end-stage renal disease. Diagn Interv Radiol 2008;14:182-185.

79 Chawla R, Smith D, Marik PE: Near fatal posterior reversible encephalopathy syndrome complicating chronic liver failure and treated by induced hypothermia and dialysis: a case report. J Med Case Rep 2009;3. 6623.

80 Sanjay KM, Partha PC: The posterior revers ible encephalopathy syndrome. Indian $\mathrm{J} \mathrm{Pe}$ diatr 2008;75:953-955.
81 Choudhary M, Rose F: Posterior reversible encephalopathic syndrome due to severe hypercalcemia in AIDS. Scand J Infect Dis 2005;37:524-526

82 Kahana A, Rowley HA, Weinstein JM: Cortical blindness: clinical and radiologic findings in reversible posterior leukoencephalopathy syndrome: case report and review of the literature. Ophthalmology 2005; 112:e7e11.

83 Chiba A: Iatrogenic reversible posterior leukoencephalopathy syndrome. Nippon Naika Gakkai Zasshi 2007;96:1657-1663.

84 Kang SY, Kang JH, Choi JC, Lee JS: Posterior reversible encephalopathy syndrome in a patient with acute intermittent porphyria. J Neurol 2010;257:663-664.

85 Muscal E, Traipe E, de Guzman MM, Myones BL, Brey RL, Hunter JV: MR imaging findings suggestive of posterior reversible encephalopathy syndrome in adolescents with systemic lupus erythematosus. Pediatr Radiol 2010;40:1241-1245.

86 Stanzani L, Fusi L, Gomitoni A, Roncoroni M, Villa P, Grampa G: A case of posterior reversible encephalopathy during polyarteritis nodosa vasculitis. Neurol Sci 2008;29:163167.

87 Garg RK: Posterior leukoencephalopathy syndrome. Postgrad Med J 2001;77:24-28.

$>88$ Servillo G, Bifulco F, De Robertis E, Piazza O, Striano P, Tortora F, Striano S, Tufano R: Posterior reversible encephalopathy syndrome in intensive care medicine. Intensive Care Med 2007;33:230-236. 